\title{
Review of: "A Compilation and Characterisation of Lithic Populations in Common and Kimberlite Maar- Diatremes and their Tephra Ring Deposits"
}

Young Kwan Sohn

Potential competing interests: The author(s) declared that no potential competing interests exist.

The authors use the term 'lithics' as a synonym of 'accidental clasts'. This is a very wrong usage of the terms. Lithics are 'rock fragments'. Lithics can be accidental when they are derived from county rocks, and can be juvenile when they are derived from dense or non-vesiculated lava/magma. In other words, lithics can be either accidental or juvenile and cannot be equated with the term 'accidental'. The term lithics in the paper should be replaced with the term 'accidental particles'.

Accidental particles may not always be 'lithics' when they are derived from unconsolidated sediments. Accidental particles in many tuff rings/cones and maars comprise detrital quartz/feldspar grains, i.e., they comprise mineral grains rather than rock fragments. The use of the term lithics as a synonym of accidentals in this paper is a complete nonsense.

In page 2, the authors state that "There is no evidence that space has been made by inelastic deformation of diatreme-adjacent country rock". I cannot agree to this argument because there are cases of maardiatreme formation in soft substrate or unconsolidated sediment where plastic deformation is possible.

In page 3, the authors listed a number of keywords they used for literature search on Google Scholar. They omitted the terms 'tuff rings' and 'tuff cones'. I guess that they omitted these terms because they think these volcanoes are devoid of diatremes in the subsurface. I am against these prejudices. Although these volcanoes eject smaller amounts of accidental clasts than maar-diatreme volcanoes, they are not accidental-free, implying that they are underlain by a diatreme. To quote Lorenz et al. (2016; GSL Spec Publ 446, doi.org/10.1144/SP446.4), there can be a continuum between maar-diatreme volcano, tuff-ringdiatreme volcano, tuff-cone-diatreme volcano, and tuff-cone volcano (no diatreme). So, I don't think the literature survey of the authors is thorough because a big portion of the pheatomagmatic volcano continuum or diatreme volcano continuum is neglected.

About the 'heterogeneity in terminology (page 9): It should be acknowledged that authors may have some responsibility for this. 
